\title{
THE ROLE OF DISRUPTIVE TECHNOLOGIES IN THE FORMATION OF THE WORLD COMPETITIVE LEADERS
}

\author{
Genefa Shvidanenko $^{1}$, Oleg Shvidanenko ${ }^{2}$, Edgardo Sica ${ }^{3}$, Tatiana Busarieva ${ }^{4}$ \\ ${ }^{1}$ Prof. Dr. Kyiv National Economy University Named After Vadym Hetman. Address: 54/1 Prospect \\ Peremogy 03057 Kyiv, Ukraine.Tel.+38 (044) 3710062.E-mail shvidanenko-go@mail.ru \\ ${ }^{2}$ Prof. Dr. Kyiv National Economy University Named After Vadym Hetman. Address: 54/1 Prospect \\ Peremogy03057Kyiv, Ukraine.Tel.+380675656524.E-mail o.shvidanenko@gmail.com \\ ${ }^{3}$ Assistant Prof. Dr. Department of Economics, University of Foggia. Address: Largo Papa Giovanni \\ Paolo II, 71121 Foggia, Italy. Tel.: +390881781711.E-mail: edgardo.sica@unifg.ites \\ ${ }^{4}$ Assoc. Prof. Dr. Kyiv National Economy University Named After Vadym Hetman. Address: 54/1 \\ Prospect Peremogy 03057 Kyiv, Ukraine.Tel.+380934018596.E-mail: sutner@ukr.net
}

Received 0711 2019; Accepted 29062020

The fundamental basis of the global changes takes place in the world is the formation of a qualitatively new type of technological structure. Innovations and information begin to play the role of the main productive resource in the modern world, and the existing socio-economic systems are transformed into the knowledge economy. The relevance of the article is due to the transition from industrial to post-industrial society and the intensive development of information and communication technologies significantly strengthen the role of disruptive technologies in the formation of the world competitive leaders. The main aim of the article is the analysis the role of disruptive technologies that in the period of the development of the knowledge economy play the important role in the formation of the world competitive leaders. The methodological basis of the article is the methods and forms of scientific knowledge adopted in domestic science, such as system approaches, comparative and synthesis methods, methods of abstract logical evaluation, methods of detailing, groupings and generalizations, experts' evaluations. The results: the criteria and the specific characteristics of the disruptive technologies were revealed, the influence of the disruptive technologies on the competitiveness of the national economies was proved, the specific features of the disruptive technologies were presented.

Keywords: disruptive technologies, knowledge economy, competition, global development, technological innovations

JEL Codes: D83, J24, O30.

\section{Introduction}

At the beginning of the XXI century, when the fifth technological order has entered the phase of maturity, it is possible, with a certain degree of confidence, to mention about the main features of the sixth technological order, whose intensive generation in the developed countries of the world is expected by the early 2020-th. It will be based on the dominance of multidisciplinary knowledge and technology - the synthesis of information and communication and computer modeling technologies with nano- and biotechnologies. Nowadays the governments of developed countries are counting on the potential of breakthrough technologies as sources of economic growth. In the US, they are launching national initiatives on the most promising technological areas, in the EU, within the framework of the Horizon 2030 program, they identify key supporting technologies.

Copyright (C) 2020. Published by Vytautas Magnus University. This is an open access article distributed under the terms of the Creative Commons Attribution Non-Commercial 4.0 (CC BY-NC 4.0) license, which permits unrestricted use, distribution, and reproduction in any medium provided the original author and source are credited. The material cannot be used for commercial purposes. 
In the countries of the Asian mega-region, the National Technology Initiative is being launched to support new markets that are emerging based on breakthrough technologies. The purpose of the article is to evaluate and critically access the role of disruptive technologies in the formation of the world competitive leaders.

\section{Analysis of the transforming role of the disruptive technologies and their influence on the formation of the world competitive leaders}

At the beginning of the XXI century, modern scientific discussions about the logic of economic development are built around the dichotomy of two approaches. Firstly, this is technological determinism (technology-push concepts), according to which scientific and technological progress and "disruptive" technologies are recognized as the determining factor of development. Secondly, the theory of the primacy of the market (demand in the broadest sense of the word - demand-pull). With some degree of conditionality, it can be said that in the modern literature the first approach is most vividly represented by the concept of technologies of wide application (General Purpose Technologies (GPT) and promising, or emerging (emerging) technologies, as well as umbrella theories of technological cycle; the second is the theory of disruptive innovation.

Under the technology of widespread use are those technologies that meet the three criteria:

1) are widely used throughout the economy (outside the industry of origin);

2) have significant development potential and are in a state of constant technological improvement;

3) stimulate innovation in the creation of products, services and processes in various fields of application.

In the year of 2014, the popularity in the economic literature received close to the concept of GPT, but independent theories of technological structures, or waves, according to which each new stage of economic development, expressed in elevated values of GDP growth, labor productivity and other macroeconomic indicators, is due to the development groups of technologies that have a systemic transformational effect on various industries (there are visible parallels with the concept of TWS).

Similarly, the concept of promising technologies (Rotolo, 2015) focuses on disruptive solutions characterized by high rates of development, the ability to change the dynamics of individual markets, industries, or even the economy. Theoretically, this phenomenon is poorly described and largely correlates with the theory of TWS. However, due to frequent appeals to this concept, it is impractical to ignore it. The above phenomena can be described as radical/ evolutionary technologies.

Market theories of innovation development have a fundamentally different focus. The most referential to the tasks of this work is the theory of "subversive" innovations, which, after the release of Christensen "Innovation Dilemma" (Christensen, 2004) in 1997, was transformed into an independent research direction ( $\mathrm{Yu}$ and Hang, 2010) including the study of problems innovation management.

Disruptive innovations are commercially reasonable innovations (including business models) that change the balance of values in the market. K. Christensen indicates that their introduction (usually carried out by a newcomer) is possible in two cases. In the first scenario, a "disruptive" product appears in the budget segment of the existing market ("low-end disruption"). It has the worst characteristics in comparison with the dominant products on the market, although it may be less expensive in production, convenient to use and have new useful functionality. Due to a different price-quality ratio and additional functionality, such a product becomes a niche leader, and then conquers the market. The second variant of "undermining" is the formation of fundamentally new markets in those areas of consumption in which there is hidden effective demand. 
There is no direct connection between the disruptive potential of innovation and its adaptability, as well as the knowledge-intensiveness of the creator company. Most of the innovations of this type turned out to be a combination of already existing technologies (Christensen 2014, p- 42). For this reason, Christensen himself refused to use the concept of "subversive technology" in favor of a more correct term "subversive innovation" - emphasizing the predominantly market-based rather than technological nature of the phenomenon.

Since the described two groups of theories and concepts do not contradict each other, the intensity of innovative and technological development of fast-growing economies can be assessed depending on their ability to create and implement breakthrough technologies and disruptive innovations. The key is the problem of the real relationship between the current and future potential of these countries in the context of the realization of the goals.

The development of disruptive technologies requires a powerful scientific and technological base and advanced socio-technical systems. In addition, it depends on highly qualified personnel with creative (that is, related not only to reverse engineering or progressive improvements) competencies, systems of advanced scientific and technological organizations and innovation-active enterprises, a powerful technological infrastructure. The presence of so-called early and skilled users is also required (Rogers, 1995; von Hippel, 2005; Slater and Mohr, 2006, p. 27-29), financial markets (Perez, 2011) and government support (Mazucatto, 2011; Ruan et al., 2014)

And yet, even in theories and concepts related to technological determinism, de facto purely institutional parameters are of paramount importance. First, this concerns the NIS institutions related to ensuring diffusion (including new areas of application) and the formation of advanced practices using breakthrough technologies, maximizing the economic and social effects of their introduction which is the main result of intensive innovation development. With regard to the problem under consideration, this is all the more important, since with the growth of global flows of ideas, personnel, technology and capital it is possible to redistribute the main effects and transfer the breakthrough technologies themselves to the most developed economies that have the best conditions for their development and scaling. Indicative in this respect is the experience of the former Soviet Union countries. Being the birthplace of many breakthrough technologies, Ukraine for purely institutional reasons could not properly use them [Graham 2014]. Similarly, the economic effects of the development of own breakthrough technologies in fast-growing economies can be relatively lower than in the most developed countries due to institutional "non-optimality" associated with the operation of NIS and market institutions. This is confirmed historically: there are cases where the greatest economic and social effects have occurred in the country of acceptor of breakthrough technologies - examples of the automotive industry and personal electronics are indicative.

The prerequisites for the emergence of disruptive innovations are largely determined by the cultural and institutional characteristics of the country, although several resource factors also turn out to be significant (qualified personnel, financial capital, and in many respects the scientific and technological potential). Decomposing the construction of the Christensen school, the key conditions for the development of disruptive innovations are the developed market institutions and NIS, the friendly regulatory environment (in general in the economy and in the innovation sphere in particular), the culture and practice of innovative entrepreneurship.

Thus, it is precisely the institutional factors and the associated culture of innovations that are key to the transition to a model of intensive innovation development. They also dictate a high degree of uncertainty about the prospects for the transition of fast-growing economies to intensive innovation and technological development. If only resource and quantity indicators were determining factors of the process, building up their potential would be a simple derivative of available and invested funds. Predicting the development, role and influence of these countries on global innovation processes would be a technical challenge, especially in a situation of positive dynamics in the growth of innovation funding and the production of qualified personnel. Institutional challenges leave no room for extrapolations, since the answer to them is not necessarily related to the growth of funding and 
even the improvement of the regulatory environment. That is why, despite the rapid increase in the number of articles, patents and the release of advanced technological products (see, for example: (Anderson, 2013; OECD, 2017, p. 398-416), China and India, not to mention other fast-growing economies, have not yet been able to imagine truly original and global technologies and innovations (with few exceptions). Moreover, since for fast-growing economies there is the task of forced and far from always organic development of NIS institutions and an innovative culture, overcoming these challenges becomes even more problematic.

The most important indicator is the emergence of disruptive innovations, the ability for which in fast-growing economies is becoming more pronounced. As an example, the phenomenon of "lean" innovation, whose subversive potential is noted by various authors (Govindarajan and Ramamurti 2011; Hang et al. 2015, p.83-84; Hossain et al. 2016, p.133) and is quite consistent with the theory of Christensen. Examples such as electric bicycles, water filtration technologies (Govindarajan and Ramamurti, 2011, p. 192; Hang et al. 2015, p. 88-90; Corsi and Di Minin, 2011; Wan et al. 2015, p. 94-104), despite the rather limited market results, are important signals of change. For disruptive innovations in developing countries, even the very socio-economic constraints and institutional problems often turn out to be drivers of development.

The unevenness of the innovation-technological development - considering other factors explains the success of China (for example, in the semiconductor manufacturing, information and genetic technologies, in the cluster of the south-western provinces of the country) and in India (information cluster in Bangalore, pharmaceuticals). Similarly, it provides a better understanding of the emergence of lean and other disruptive innovations in developing countries (Sardak, 2014).

\section{Conclusions}

To conclude it is necessary to mention that the introduction of new technologies will lead to the creation of a new economy, including the formation of new principles and approaches for organizing digital industrial production ("smart" factories in accordance with the concept of Industry 4.0). It will be possible to create a new "interface" economy based on the use of additive technologies on an industrial scale when a decentralized industrial production system unprecedented is achieved. And if this happens, the whole economic system will change, and with it the social structure of society. However, this seems a distant prospect. The more important task of the near future (10-15 years) is to learn to foresee and manage possible structural changes (which is more a function of the state than the private sector) in order to minimize the inevitable losses in the future.

\section{References}

Dan Yu, Chang Chieh Hang. (2010). A Reflective Review of Disruptive Innovation Theory // International journal of management reviews. Volume 12, Issue 4. pp. 435-452.

Dosi G. (1982). Technological paradigms and technological trajectories // Research Policy. Vol. 11, Issue 3. pp.147-162.

Fitzgerald E., Wankerl A., Schramm C. (2011). Inside real innovations. Singapore World Scientific Publishing Co Pte Ltd. 248 p.

Fuchs E.R.H. (2010). Rethinking the Role of the State in Technology Development: DARPA and the Case for Embedded Network Governance// Research Policy. Vol. 39. pp. 1133-1147.

Govindarajan V., Kopalle P. K. (2006). The Usefulness of Measuring Disruptiveness of Innovations Ex Post in Making Ex Ante Predictions // Journal of Product Innovation Management. Vol. 23. No. 1. pp.1218.

Govindarajan V., Ramamurti R. (2011). Reverse innovation, emerging markets, and global strategy. Global Strategy Journal. Vol.1. pp. 191-205 $88-90$.

Hang C.C., Garnsey E., Ruan Y. (2015). Opportunities for disruption // Technovation. Vol. 39-40. pp. 
Dosi G. (1982). Technological paradigms and technological trajectories // Research Policy. Vol. 11. Issue 3. pp.147-162.

Fuchs E.R.H. (2010). Rethinking the role of the state in technology development: DARPA and the case for embedded network governance // Research Policy. Vol. 39. Issue 9. pp. 1133-1147.

Govindarajan V., Ramamurti R. (2011). Reverse innovation, emerging markets, and global strategy // Global Strategy Journal. Vol.1. pp. 191-205.

Hang C.C., Garnsey E., Ruan Y. (2015) Opportunities for disruption // Technovation. 2015. Vol. 3940, May-June. pp. 83-93.

Sardak S.E. (2014). National Economies Intellectualization Evaluating in the World Economy / S. E. Sardak, A. A. Samoylenko // Economic Annals-XXI. Vol. 9-10. - C. 4 - 7.). 